\title{
SCHOOL GARDENING: WHAT IS CURRENT TREND ABOUT?
}

\author{
Beata Lavrinoviča \\ University of Latvia, Latvia
}

\begin{abstract}
There is plenty of research on school gardening practices reflecting the positive effects of garden-based learning on the development of elementary school students, which are mainly based on short-term gardening program implementation and assessment. However, theoretical research of school gardening is still not shaped well, as the distribution of research activities is unequal and the concept itself is still considered being innovative. A review of scientific literature and documents has been done to define what the school gardening concept really means and what are the spatial and functional domains of it.

The review has touched on historical aspects of the school gardening movement's rise at the beginning of the $20^{\text {th }}$ century in the U.S., as the country considered being at the frontiers of the current trend. Differences in defining school gardening priorities were identified, pointing out the variety of functional domains of school gardening activities developed during the century. Currently, school gardening is characterized by its role in improving students' learning and achievements, environmental attitudes, health and food behaviours, intrapersonal skills and emotional wellbeing, and social bonds. Also, as the term "school gardening" itself refers to a specific place-based setting, its spatial domain was inspected and redefined according to the variety of current garden-based learning practices.

The review allowed to define school gardening as a school-run and community-supported tool for student engagement with school curriculum, civic activism, healthy lifestyle, and development of intrapersonal and social skills through experiential, experimental, transdisciplinary, collaborative, and self-directed learning.
\end{abstract}

Keywords: Elementary schools, garden-based learning, learning spaces, school gardening, student engagement.

\section{Introduction}

School gardening initiatives and programmes have been in focus of international research communities during the last three decades. The most intensive research work is done by the U.S. research institutes thanks to a well-developed school garden network and infrastructure that is overtaken from Europeans and rooted back in the last decade of the $19^{\text {th }}$ century. The 
first decade of the $20^{\text {th }}$ century has been significant for the rise of children agricultural activities in rural schools and research on them. Interestingly, the American literature refers to the positive influence of European school gardening practices, especially Austro-Hungarian, Prussian, French, southern- and central-Russian, and Swedish, as examples to follow (Clapp, 1898; Miller, 1904). Pointing out progressive and highly beneficial European school gardening initiatives, Miller (1904) has expressed that "when the importance of school gardens as a factor in the training of children is considered, and their efficiency has been so thoroughly demonstrated by European countries, it seems almost incredible that their establishment in the United States should have been so long delayed".

Within a century, the situation has changed to completely opposite. School gardening in the U.S. has large state support for implementation, covering school garden' setup, preparing teaching staff, aligning gardening activities to each state's education standards and establishing a food curriculum for the school system (Passy, 2014) and research, while school gardening for educational purposes in European countries is highly fragmented, with several exceptions in UK, Denmark, Sweden, Slovenia. Also, the purpose of school gardening has changed with the time and socio-economic conditions in Europe and U.S. Developed from the pedagogic trend towards teaching science through nature-based inquiry in the second half of the $19^{\text {th }}$ century (Rockwell, 2020), now school gardening is recognized as a pedagogical tool for multi-purpose learning.

Despite more than a century-long research of educational activities in gardens, there is no commonly accepted term and definition of gardening activities for learning purposes. The terms used most often in relation to pedagogy are school gardening (Passy, 2014; Baker et al., 2015), garden-based learning (Ruiz-Gallardo et al., 2013), children's gardening (Lekies, Sheavly, 2007), kitchen garden programmes (Wallace, 2019; Block et al., 2011) and garden-based education (Murakami et al., 2018; Kim et al., 2020). School gardening seems to be the most appropriate term to use in further explorations, based on the explicit experience of American practitioners and researchers of school gardening.

Although there are plenty of researches explaining gardening effects on children in education during the last decades, none of them really defines what school gardening really is. As Johnson (2012) has pointed out, there is little recent research into the theoretical basis for gardening and the capacity of schools to incorporate such. Since then little has changed. On the one hand, the concept has been explicitly described in the scientific literature at the beginning of the $20^{\text {th }}$ century. On the other hand, new pedagogical methods and concepts have been developed and new models and roles of school gardening have been discovered. Additionally, researches conducted 
in distinct countries and settings allow concluding on the variety of school gardening practices, settings and collaborative models. The objective of the review is to define the school gardening concept and review its current spatial and functional domains.

\section{Methodology}

Electronic search and snowball sampling methods have determined the results of this review of scientific literature and documents. Mainly Taylor \& Francis Online database (with several exceptions found through Researchgate and Google search) was facilitated to research the topic, using the key words such as 'school gardening', 'urban garden', 'community garden', 'kitchen garden', 'garden', and others. In total, more than 60 scientific articles and pedagogy-related literature in English and Russian were reviewed to select 45 for further exploration. The selection was determined by the content explaining particular gains from practicing gardening for educational purposes. Mainly the articles of the last decade were reviewed with some exceptions of earlier articles explaining the origins of the school gardening concept and scientifically well-recognized authors. The majority of reviewed articles were based on quasi-experimental, mixed research designs or scoping reviews from U.S., Europe, Asia, and Australia. Reviewed scientific articles had diverse purposes, from measuring school gardening programmes to assessing specific influences of school gardening activities on nutrition habits or self-perception of students. This specific study has applied gathered knowledge to determine the main components of school gardening definition to be applied in further research actions.

\section{Results}

If at the beginning of the school gardening movement in Europe and consequently in the U.S. the emphasis was put on rural schools equipping them with gardening tools for maintaining by children, the World War I has demonstrated that gardens can be set in the urban environments specifically for food production purposes (by both children and adults). Since then, plenty of research has been conducted in the area of urban wellbeing, where the urban garden is viewed as a centre for community interaction, healthy lifestyle promotion, ecology, and recreation (Bell et al., 2016; Ernwein, 2014). During the last decades, in school settings effects of gardening practices are mainly researched in the scope of food behaviours and science knowledge improvement (Cairns, 2017; Kim et al., 2020; Wells et al., 2015; Skelton et al., 2020; Blair, 2009) as the major reason for implementing school gardening. However, the potential of gardening 
programmes is much broader, as the latest qualitative studies have discovered gardening activities being a powerful tool for initiating an interest and motivation, developing transversal skills and developing agency of the learners (Murakami et al., 2018; Holmes et al., 2020; Christodoulou, Korfiatis, 2019; Barnick, 2014). It makes the concept of school gardening perceived differently than a century ago.

At the beginning of the school gardening movement in the U.S., the American research community defined the school garden as "a place where children are taught to care for flowers and/or vegetables, by one who can, while teaching the life history of the plants, and of their friends and enemies, instil [sic] in the children a love for outdoor work and such knowledge of natural forces and their laws as shall develop character and efficiency" (Greene, 1910). Moreover, as stated by Schwab and Mann (1879) even prior the first school garden establishment in the U.S., the school garden is a "place where children are happiest" as they are not locked in a school classroom or home while doing the homework for the school. Miller (1904) have pointed out that school garden serves two types of children - those who live in urban settings and have little opportunities to interact with "the things of the country" and those who live in rural settings but are still ignorant to nature they are in contact with. School gardening in the pedagogy of that time was mainly driven by the need to familiarize children with nature and labour, cultivating skills that can be used for the rest of their lives. Later on, it turned to be highly practical, when the central purpose of school gardening was food production for the support of civilians and armed forces during the World Wars. United States School Garden Army was designed by the Federal Bureau of Education during World War I, calling for "A garden for every child. Every child in a garden" (United States Department of Agriculture Poster Collection, 1914).

Nowadays Food and Agriculture Organization of the United Nations (2004) defines school gardens as "cultivated areas around or near to primary and/or secondary schools, which can be used mainly for learning purposes but could also generate some food and income for the school." According to Bice and others (2017), school garden can be classified as a type of community gardens (along with Leisure gardens and Private (or Entrepreneurial) gardens) and defined as "community gardens, owned and run by schools or educational facilities, are most often found directly onsite and are paired with varieties of classroom instruction that expand traditional learning spaces to promote not only academic success but also fruit and vegetable consumption, physical activity, and the development of social and leadership skills" (Bice et al., 2017). At the same time, regardless of long history of gardening practices in education, California School Garden Network (2006) calls school garden "a living laboratory" and "an 
innovative teaching tool and strategy" enabling engagement of students through incorporating hands-on activities in a diversity of interdisciplinary, standards-based lessons, dynamic environment observation, discoveries, experimentations, nurturing and learning science, practical horticultural and life skills. Verification was done by comparing the data to the garden-based practices in another scientific culture, Russia. Galkina and Ishkova (2014) similarly define school garden as a basis for experimental work that takes a significant role in the study of living nature by students, develops cognitive interest and creativity in conducting experimental and natural science research. Moreover, with a strong emphasis on developing practical labour and research skills of students, school gardening is called "a required open-air laboratory" for familiarizing students with various species of plants, biodiversity, growing techniques (Smirnova, 2013).

There are two elements of the term that have to be analysed - "school" and "gardening" revealing the spatial and functional meaning.

\section{Spatial domain}

According to Collins dictionary (2020), "school" - is "a place where children are educated" describing the location of the action. One of the distinguishing elements of school gardening is the outdoor environment and access to nature, providing an opportunity to relax and support cognitive functions (Chang et al., 2016). However, it is important to note that outdoor school-by-setting is not strictly determining criteria for defining school gardening, as innovative practices include various in-class, lab- or farm-based activities too as part of the formal educational curriculum. For instance, gardening programmes can include systems of hydroponics and aquaponics that can be maintained indoors (Schneller et al., 2015) or animal and plant farms located on a distance from school (Malberg Dyg, Wistoft, 2018).

Also, spatial meaning can be characterized by target groups of garden-based activities. The research activities around school gardening are mainly focused on students and their teachers engaged in gardening activities, however the presence of larger stakeholder groups need to be admitted: teachers, students, support staff, parents, school principals, volunteers, specialist staff, etc. The research practice of the last century confirms that school gardening is not equally implemented (and consequently researched) in relation to all age groups of learners. The majority of scientific authors reflect the effects of gardening activities on elementary school students (Christodoulou, Korfiatis, 2019; Sarti et al., 2017, Wells et al., 2015, Swank, Shin, 2015; Blair, 2009), as elementary school grades are recognized as a time of special significance in the development of interest (disinterests) in science (Klemmer et al., 2005). Kindergarten-age children 
in pre-schooling settings are the second most popular object of the research (Baker, Waliczek \& Zajicek, 2015). Less gardening effects are measured in relation to adolescents in high schools, however, the social, emotional and academic effects of gardening on at-risk-adolescents is also one of the focus areas of research (Wang et al., 2004; Ruiz-Gallardo et al., 2013). Another direction in school gardening research focuses specifically on teachers and their abilities to deliver garden-based curriculums, as well as involvement of other stakeholder groups (e. g. parents, school principals, local entrepreneurs, etc.

There are various school gardening implementation models that include different parties supporting teachers and learners. For instance, in the U.S., where school gardening solutions have been national programme-driven for more than a decade (Passy, 2014), school gardens are mainly attached to each particular school, being an object of pride, the reason for improved sense of belonging and ownership of a space. In Russia, school gardens are defined as a part of school territory, as it allows to save time for efficient outdoor experimentation and hands-on learning (Galkina, Ishkova, 2014). In general schools with own gardens are capable of gathering own community of stakeholders, providing the space for intergenerational learning, community events, involving volunteers (parents, grandparents), fundraising, attracting local entrepreneurs, etc. (Passy, 2014; Block et al., 2011, Holmes et al., 2020). In Denmark, where the school gardening concept is still new, school gardens are mainly located on farms, nature centres and other out-of-school settings (Malberg Dyg, Wistoft, 2018), demonstrating a project-based approach and adequate management of gardening and environmental programmes in urban and rural schools. In result, urban children have equal access to the natural environment and larger social actors' group (farmers, NGOs) is involved in educational content implementation. In such cases school is still considered as an agent of gardening-based activities, mainly educational.

\section{Functional domains}

The second part of the term - "gardening" - describes specific context and functional meaning of "school gardening". According to Collins dictionary (2020), gardening is defined as "planning and cultivation of a garden" (in British English), which clearly characterizes gardening as a place-based activity. In pedagogical studies, gardening is viewed broader in a context of knowledge and skills development.

Learning and science achievement. The most common reason for launching the gardening programme in the school is a necessity or will to improve interest and academic performance, particularly in the area of science (Blair, 2009, Block et al., 2011). The need is based on UNESCO's 
(2015) definition of science as critical in reaching Sustainable Development Goals and experts' concern about inadequate interest in science, technology, engineering, and math (STEM) careers among children and young people. Although the lack of interest is often associated with the complexity of the studied areas, achievement difficulties and learners' disconnectedness from nature; primary low interest relies on the lack of curiosity, enjoyment and following participation in scientific activities of respective areas (Dabney et al., 2011).

Hands-on, experiential and interdisciplinary approaches of school gardening programmes make learning relevant, practical and exciting for children, consequently contributing to the engagement of learners with less academic aptitude and better understanding of learning purpose (Passy, 2014; Malberg Dyg, 2015; Klemmer et al., 2005; Skinner, Chi, 2011). Moreover, science-related topics can include various other disciplines, such as language studies, mathematics, entrepreneurship and economics, health and hygiene, geography, and many more, designing a clear understanding of the possible application of knowledge. According to Block and others (2011), such experiential learning practices are particularly useful for "kids who don't shine in academia". The workflow of school gardening activities allows for immediate reflection on what has been learned, what skills are mastered and how this relates to other subjects in school (Block et al., 2011, Malberg Dyg, 2015).

Environmental awareness. According to Wallace (2019), building knowledge and understanding of the environment is the basis for building connection and empathy with living things and developing deeper understanding (or eco-literacy). These connections can be only made when observing and interacting with nature, therefore outdoor activities and observations are critical for empathetic behaviours development. According to Ohly and colleagues (2016), the facilitation of deeper understanding and appreciation of natural world in childhood develops broader perceptions of wellbeing and environmental responsibility in adulthood. These findings have led to the understanding that the use of school gardens as learning spaces in elementary schools can provide a conduit for reconnecting children to nature, offering hope for more eco-literate citizens and a sustainable future.

Health and food behaviours. One of the most important functional meanings of school gardening is learning about healthy nutrition, especially in relation to children from families with low socioeconomic status and poor fresh food eating habits (Sarti et al., 2017). It is considered that food growing and preparation skills acquired through hands-on gardening activities allow developing healthy and sustainable living in further life (Malberg Dyg, 2015), however, longer observations are necessary to 
depict the evidence of healthier living. From what is known from shortterm research on student behaviours, it is noted, that school gardening activities positively enhance children to try new food - fruits and vegetables - the results of purposeful efforts in a garden - thanks to gardening routine, increased autonomy, agency, and decision-making (Ohly et al., 2016; Sarti et al., 2017). In his "I Eat the Vegetables because I Have Grown them with My Own Hands: Children's Perspectives on School Gardening and Vegetable Consumption" Sarti and colleagues (2017) reports more vegetables being eaten by Dutch children participating in the gardening programme. Moreover, gardening activities are closely linked to environmental behaviours, as they promote an understanding of the value of food and its relation to waste management problems (Sarti et al., 2017; Block et al., 2011). Other health-related issues practiced through purposeful school gardening activities are physical activity (Bice et al., 2017) and hygiene, which are parts of the modern school curriculum.

Intrapersonal skills and emotional wellbeing. Valuing the way how students learn over what should be learned (Johnson, 2012), researchers of school gardening programs have explored positive impacts on children's life-skills and transferable knowledge. Cultivating, observing, and cooking plants develops scientific curiosity, inquiry, perseverance, critical thinking, problem-solving skills, respect for evidence, teamwork, respect for order, and other characteristics and skills relevant for scientific attitudes and lifelong learning (Kim et al., 2020; Holmes et al., 2020). These skills are taught through the routine that promotes questioning, examining, reasoning, proving, and making judgements about concrete experiences. Nature-nurturing activities turn to be a perfect environment for student-led learning (incl. learning from mistakes) and developing own experience. The development of intrapersonal skills is determined by the agency of the learner, which also allows development of creativity, abstract thinking, risk-taking, confidence, self-esteem, pride, responsibility, and sense of ownership (Miller, 2007; Block et al., 2011). Ruiz-Gallardo and colleagues (2013) in his research on disruptive and low-performance secondary school children has concluded that garden-based learning reduces disruptive episodes and improves academic performance by making students feel responsible for something "meaningful" (not just completing "random tasks"), achieving tangible personal results, being proud of own work, feeling self-perception and self-esteem. It is worth mentioning that school gardening experiences, supported by teachers, parents, and peers, have a high potential to positively influence the interpersonal growth, health, and emotional wellbeing of learners (Malberg Dyg, Wistoft, 2018; Ohly et al., 2016).

Interpersonal relationships and behavioural patterns within a group. According to Johnson (2012), students' garden-based activities 
have civic and global dimensions among others. The beliefs and values of students are challenged through social interactions when gardening with their peers and stakeholders. Gardening activities develop a healthy environment within a class and promotes the development of interpersonal skills, such as cooperation, teamwork, leadership, conflict management, communicating desires, needs, ideas to others, sharing and negotiating, interacting and collaborating with adults and peers, making democratic decisions, organizing the setting and workload (Miller, 2007; Johnson, 2012; Holmes et al., 2020). Gardening as a goal-oriented activity carried out in a team helps to overcome social boundaries and elitism associated with traditional academic structures (Ohly et al., 2016), as well as empower more trustful relations among students, teachers, and family members engaged in intergenerational garden-based learning. Lifelong learning is empowered through learning from each other and sharing experiences and knowledge. In schools with ethnic and linguistic minorities, gardening provides additional social interaction opportunities for oral language skill development (Block et al., 2011) in a less stressful atmosphere than in a formal classroom. Through the implementation of planting and cooking activities in multicultural groups, cultural awareness and cohesion of learners are positively influenced (Ohly et al., 2016), especially in groups where interpersonal relations are not well managed.

\section{Discussion}

It has become clear, that garden in a school is no more just a setting for learning new knowledge - it is a functional tool and a set of actions to respond to a broader spectrum of challenges, therefore can be implemented in a transdisciplinary manner. For instance, one of the stages for urban and school gardening development is based on the social, economic and political crisis in the 1970s, when "green activism" rediscovered agricultural activities (especially in cities) as a tool for sustainable living (Bell et al., 2016). Since then, environmental awareness is one of the functional domains for teaching and learning at school gardens, however not the only one. Other functional domains describing effects on school-aged children are learning and particularly science achievement, health and food behaviour, intrapersonal skills and emotional wellbeing, and interpersonal relationships.

The spatial domain, in turn, needs to be redefined due to technological advancements and social innovation, as the traditional view on gardening activities has been complemented by a variety of approaches, incl. indoor and outdoor schoolyard gardens, and distant stakeholder-designed community spaces (Schneller et al., 2015; Malberg Dyg, Wistoft, 2018). Variety, 
in turn, is defined by climate, financial opportunities, and the capacity of teachers to undertake practical activities in a garden, especially among younger staff (Passy, 2014; Ohly et al., 2016). Also, approaches differ by the level of activity connectedness to the science and agency given to students by teachers and external educators, such as gardeners, chefs, nature guides, beekeepers, etc. (Malberg Dyg, 2015).

In the school, gardening can be integrated with the wider curriculum than just science- or environment-focused subject areas. The ideas of interdisciplinary and transdisciplinary learning have special significance within the context of overloaded curriculums. Hands-on, experiential, inquiry- and project-based gardening activities can be used for learning several themes at once, launching STEM area research with physical activities, literature, arts, history, information and communication (ICT) application, civic education, entrepreneurship, economics, history, culture, and even career guidance sessions. For instance, planting vegetables can include: planting, maintaining, and harvesting (horticulture) activities (biology, housekeeping, chemistry), knowledge about the soil and irrigation (geography, physics), construction of planting beds (mathematics, physics, economics), decorating school area (design, arts), presenting results of the gardening projects, copywriting and marketing for school website (ICT, literature), fundraising (entrepreneurship), planning tools and materials (entrepreneurship/ management), distributing tasks and sharing different roles (career planning), cooking meals and sharing with parents (community building, housekeeping, chemistry), waste management and circular economy knowledge (geography, biology), doing physical exercises outdoors (sports), researching the history of species and localities (history, geography) and many more. At the same time, these activities can be done in a highly social atmosphere (group work, experience exchange), by applying student agency and peer-learning, supported by teachers and/or other educators.

It is necessary to admit, that the research on school gardening is incomplete. One of the most common concerns expressed by the researchers is the lack or insufficiency of quantitative evidence of school gardening's positive effects. So far, the knowledge is mainly based on qualitative and shortterm intervention studies. Surveys and tests are often applied in research with the action and control groups, however, these do not always show significant differences in relation to the perception of science/environmental studies, interest in gardening or study achievements. Long-term studies with a large sample and consistent evaluation methodology are necessary to assess strengths and limitations of school gardening programmes to be implemented on a larger scale. So far school gardens are distributed unequally and often lack competencies as require proper preparation of staff, therefore require social innovation to proceed. 


\section{Conclusions}

The majority of recent research on school gardening accessible in English are conducted in the U.S. and do not define the term "school gardening" itself, rather focusing on specific effects of garden-based activities on elementary school students or teacher competence in school gardening. This review has been focused on defining the school gardening concept and reviewing its current spatial and functional domains.

Based on review articles, modern school garden can be recognized as a functional tool rather than just a space for learning how to grow food and generate income from it. Except for poorly developed territories, where gardening primary serves as a tool for survival, school gardening can be defined as school-run and community-supported tool for student engagement with school curriculum, civic activism, healthy lifestyle and development of intrapersonal and social skills through experiential, experimental, transdisciplinary, collaborative and self-directed learning. School gardening activities can be implemented in a variety of settings, incl. those indoors or on a remote distance from the school territory.

Although the key stakeholders of garden-based learning still remain elementary school children and their teachers, successful school gardening programmes involves a much broader community, such as parents, public authorities, local farmers, volunteers and others. This supports the definition of school garden as a type of community garden that expands traditional learning spaces to promote not only academic success but also other abilities of students: eating habits, physical activity, development of social and other transversal skills.

\section{References}

Baker, M. R., Waliczek, T. M., and Zajicek, J. M. (2015) The Effect of School Gardening Activities on Visual-Motor Integration of Pre-School and Kindergarten Students. Journal of Therapeutic Horticulture, 25(2), pp. 3-13.

Barnick, A., (2014) The Impact of a School Gardening Program on Nutrition Attitudes, Behaviors and Interests Amongst Fourth Grade Students. Cleveland State University, ETD Archive. 27. Available at: https://engagedscholarship.csuohio.edu/etdarchive/27 [Accessed 23 Dec. 2020]

Bell, S., Hursthouse, A., Zilans, A., and Voigt, A. (2016) "Grassroots gardening movements - towards cooperative forms of green urban development?" A history of urban gardens in Europe

Bice, M. R., Ball, J., Bickford, N., Bickford, S. H., Hollman, A., Coughlin, A., Dinkel, D., Meyer, R. C., and Ranglack, D. H. (2017) Community Gardens: Interactions between Communities, Schools, and Impact on Students. The Health Educator, 50(1), pp. 2-10.

Blair, D. (2009) The Child in the Garden: An Evaluative Review of the Benefits of School Gardening. The Journal of Environmental Education, 40(2), pp. 15-38. 
Block, K., Gibbs, L., Staiger, P. K., Gold, L., Johnson, B., Macfarlane, S., Long, C., and Townsend, M. (2011) Growing Community: The Impact of the Stephanie Alexander Kitchen Garden Program on the Social and Learning Environment in Primary Schools. Health Education \& Behavior, 20(10), pp. 1-14.

Cairns, K. (2017) Connecting to food: cultivating children in the school garden. Children's Geography, 15(3), pp. 304-318.

California School Garden Network (2006) Gardens for learning. Creating and Sustaining Your School Garden, Western Growers Foundation. Available at: http://www.csgn.org/ sites/default/files/CSGN_book.pdf [Accessed 14 Dec 2020]

Chang, Y. Y., Su, W. C., Tang, I. C., and Chang, C. Y. (2016) Exploring the Benefits of School Gardening for Children in Taiwan and Identifying the Factors Influencing these Benefits. HortTechnology, 26(6), pp. 783-792.

Christodoulou, A., and Korfiatis, K. (2019) Children's interest in school garden projects, environmental motivation and intention to act: A case study from a primary school of Cyprus. Applied Environmental Education \& Communication, 18(1), pp. 2-12.

Clapp, H. L. (1898) School gardens. Popular Science, vol. 52, pp. 445-456.

Collins dictionary publishing. (2020). School. www.collinsdictionary.com. Available at: https://www.collinsdictionary.com/dictionary/english/school [Accessed 14 Dec 2020]

Collins dictionary publishing. (2020). Gardening. www.collinsdictionary.com. Available at: https://www.collinsdictionary.com/dictionary/english/gardening [Accessed 14 Dec 2020]

Dabney, K. P., Tai, R. H., Almarode, J. T., Miller-Friedmann, J. L., Sonnert, G., Sadler, P. M., and Hazari, Z. (2011) Out-of-School Time Science Activities and Their Association with Career Interest in STEM. International Journal of Science Education, Part B, 2(1), pp. 63-79.

Ernwein, M. (2014) Framing urban gardening and agriculture: On space, scale and the public. Geoforum, 2014, 56, pp. 77-86.

Food and Agriculture Organization of the United Nations (2004) School Gardens Concept Note: Improving Child Nutrition and Education through the Promotion of School Garden Programmes. Available at: http://www.fao.org/3/af080e/af080e00.pdf [Accessed 10 Jan. 2021]

Greene, M. L. (1910). Among School Gardens. New York: Charities Publication Committee. pp. 3 Available at: https://archive.org/details/CAT10946826 [Accessed 10 Jan. 2021]

Holmes, E. A., Campbell, M. F., James, W., and Matthews, K. (2020) Sow, Grow, Know, and Show": The Impact of School Gardens on Student Self-Perception in the Mississippi Delta. Ecology of Food and Nutrition, 60(2), pp. 140-162, DOI: 10.1080/ 03670244.2020.1807343

Johnson, S. (2012) Reconceptualising gardening to promote inclusive education for sustainable development. International Journal of Inclusive Education, 16 (5-6), pp. 581-596.

Skelton, K. R., Lowe, C., Zaltz, D. A., and Benjamin-Neelon, S. E. (2020) Garden-based interventions and early childhood health: an umbrella review. International Journal of Behavioral Nutrition and Physical Activity, 17(121), pp. 1-19.

Kim, K. J., Jung, E., Han, M. K., and Sohn, J. H. (2020) The Power of Garden-Based Curriculum to Promote Scientific and Nature-Friendly Attitudes in Children Through a Cotton Project. Journal of Research in Childhood Education, 34(4), pp. 538-550. 
Klemmer, C. D., Waliczek, T. M., and Zajicek, J. M. (2005) Growing Minds: The Effect of a School Gardening Program on the Science Achievement of Elementary Students. HortTechnology, 15(3), pp. 448-452.

Lekies, K. S., and Sheavly, M. E. (2007) Fostering Children's Interests in Gardening. Applied Environmental Education and Communication, 6(1), pp. 67-75.

Lohr, A. M., Krause, K. C., McClelland, D. J., Van Gorden, N., Gerald, L. B., Del Casino, V., Wilkinson-Lee, A., and Carvajal, S. C. (2020) The impact of school gardens on youth social and emotional learning: a scoping review. Journal of Adventure Education and Outdoor Learning, Available at: https://doi.org/10.1080/14729679.2020. 1838935 [Accessed 10 Jan. 2021]

Malberg Dyg, P. (2015) Transforming Primary Education and Pedagogy - the Case of School Gardens in Denmark, Metropolitan University College, Denmark. Available at: https://www.ucviden.dk/ws/portalfiles/portal/92558514/TRANSFORMING_PRIMARY_ EDUCATION_AND_PEDAGOGY_the_case_of_school_gardens_in_Denmark_P.M._Dyg_2015_ presented_at_END_Conference_27_July_2015.pdf [Accessed 10 Jan 2021]

Malberg Dyg, P., and Wistoft, K. (2018) Wellbeing in school gardens - the case of the Gardens for Bellies food and environmental education program. Environmental Education Research, Available at: https://doi.org/10.1080/13504622.2018.1434869 [Accessed 24 Dec 2020]

Miller, L. K., (1904) Children's gardens for school and home: a manual of cooperative gardening. New York, D. Appleton. Available at: https://archive.org/details/ CAT10946837 [Accessed 14 Dec 2020]

Miller, D. L. (2007) The Seeds of Learning: Young Children Develop Important Skills Through Their Gardening Activities at a Midwestern Early Education Program, Applied Environmental Education and Communication, 6(1), pp. 49-66.

Murakami, C. D., Su-Russell, C., and Manfra, L. (2018) Analyzing teacher narratives in early childhood garden-based education. The Journal of Environmental Education, 49(1), pp. 18-29.

Ohly, H., Gentry, S., Wigglesworth, R., Bethel A., Lovell, R., and Garside, R. (2016) A systematic review of the health and well-being impacts of school gardening: synthesis of quantitative and qualitative evidence. BMC Public Health 16(286), pp. 1-37.

Passy, R. (2014) School gardens: teaching and learning outside the front door. Education 3-13. International Journal of Primary, Elementary and Early Years Education, 42(1), pp. 23-38.

Rockwell, E., (2020) The multiple logics of school gardening: a 'return to nature' or 'love of labour'?. History of Education, 49(4), pp. 536-552.

Ruiz-Gallardo, J. R., Verde, A., and Valdés, A. (2013) Garden-Based Learning: An Experience With "At Risk" Secondary Education Students. The Journal of Environmental Education, 44(4), pp. 252-270.

Sarti, A., Dijkstra, C., Nury, E., Seidell, J. C., and Dedding, C. (2017) 'I Eat the Vegetables because I Have Grown them with My Own Hands': Children's Perspectives on School Gardening and Vegetable Consumption. Children and Society, vol. 31, pp. 429-440.

Schneller, A. J., Schofield, C. A., Frank, J., Hollister, E., and Mamuszka, L. (2015) A Case Study of Indoor Garden-Based Learning With Hydroponics and Aquaponics: Evaluating Pro-Environmental Knowledge, Perception, and Behavior Change, Applied Environmental Education \& Communication, 14(4), pp. 256-265.

Schwab, E., and Mann, M. T. P. (1879) The school garden, M.L. Holbrook \& Co, New York. 
Skinner, E. A., Chi, U., and Learning-Gardens Educational Assessment Group 1 (2011) Intrinsic Motivation and Engagement as "Active Ingredients" in Garden-Based Education: Examining Models and Measures Derived From Self-Determination Theory. The Journal of Environmental Education, 43(1), pp. 16-36.

Swank, J. M., and Shin, S. M. (2015) Garden Counseling Groups and Self-Esteem: A Mixed Methods Study With Children With Emotional and Behavioral Problems. The Journal for Specialists in Group Work, 40(3), pp. 315-331.

United States Department of Agriculture Poster Collection (1914) Poster: We Belong to the U.S. School Garden Army, Courtesy of the National Agricultural Library.

UNESCO (2015) UNESCO Science Report: Towards 2030. UNESCO Publishing.

Wallace, H. D. (2019) Transdisciplinary learning in a kitchen garden: connecting to nature and constructing a path to ecoliteracy? International Research in Geographical and Environmental Education, 28(4), pp. 309-323.

Wang, C. K. J., Ang, R. P., Teo-Koh, S. M., and Kahlid, A. (2004) Motivational predictors of young adolescents' participation in an outdoor adventure course: A self-determination theory approach. Journal of Adventure Education \& Outdoor Learning, 4(1), pp. 57-65.

Wells, N. M., Myers, B. M., Todd, L. E., Barale, K., Gaolach, B., Ferenz, G., Aitken, M., Henderson, C. R., Tse, C., Ostlie Pattison, K., Taylor, C., Connerly, L., Carson, J. B., Gensemer, A. Z., Franz, N. K., and Falk, E. (2015) The Effects of School Gardens on Children's Science Knowledge: A randomized controlled trial of low-income elementary schools. International Journal of Science Education, 37(17), pp. 2858-2878.

Galkina, E., and Ishkova, А. (2014) Образователный потенциал пришкольного учебноопытного участка [Educational potential of the school learning and experimental site] Concept Journal, 2014 (1), pp. 1-2 Available at: https://e-koncept.ru/2014/14023.htm [Accessed 23 Dec. 2020]

Smirnova, V. (2013) Учебно-опытный пришкольный участок - лаборатория для биолога. [School learning and experimental site - laboratory for biologist]. Нобель npecc. Available at: https://www.bookvoed.ru/files/3515/11/41/01.pdf [Accessed 10 Jan 2021] 